\section{Gabapentin for acute and chronic post-surgical pain}

\author{
AIKATERINI MELEMENI • \\ CHRYSSOULA STAIKOU \\ Lecturer, Department of Anaesthesiology, \\ Aretaieio Hospital, School of Medicine, \\ National and Capodistrian University of \\ Athens, 76 Vassilissis Sofias Avenue, 11528 \\ Athens, Greece. \\ ARGYRO FASSOULAKI ( $\square$ ) \\ Professor and Chairperson, \\ Department of Anaesthesiology, \\ Aretaieio Hospital, School of Medicine, \\ National and Capodistrian \\ University of Athens, \\ 76 Vassilissis Sofias Avenue, \\ 11528 Athens, Greece. \\ Phone: + 302107286334 \\ Fax: + 302107211007
}

Email: fassoula@aretaieio.uoa.gr

\begin{abstract}
Pain after surgery remains a significant clinical problem as it impairs recovery adversely and may lead to the transition to chronic pain. Opioid medications are far from ideal agents in suppressing postoperative pain. Gabapentin -an anticonvulsant with antihyperalgesic properties- originally efficacious against neuropathic pain seems to be very promising for the management of pain after surgery as well. Gabapentin, by decreasing noxious stimulus-induced excitatory neurotransmitter release at the spinal cord, may attenuate central sensitization, and eventually decrease postoperative late pain. Furthermore, different sites of action may be pertinent to a synergistic effect with opioids. Both actions (antihyperalgesic effect and synergy with opioid analgesia) may manifest as analgesia and/or opioid-sparing effect after surgery. This has been confirmed by a variety of clinical studies, in a variety of settings. Most of these studies have shown that either single preoperative or repeated doses of gabapentin, continued for up to a few days after surgery, decrease acute postoperative pain and/or need for postoperative opioids. This has been shown for procedures such as abdominal and vaginal hysterectomy, breast surgery for cancer (mastectomy or lumpectomy), lumbar discectomy and spinal fusion, laparoscopic cholecystectomy and other, such as ENT surgery. Finally, a few studies indicate that perioperative gabapentin may as well decrease chronic pain several weeks after surgery.
\end{abstract}

Key Words: pain postoperative, pain chronic, post-mastectomy pain, anticonvulsants, gabapentin

Pain is a common postoperative symptom impairing the quality of postoperative recovery, delaying discharge from Post-anaesthesia care unit (PACU) or surgical centre, leading to post-discharge readmissions, and increasing overall morbidity and costs (1-4).

Ongoing, acute postoperative pain may lead to chronic pain after surgery. Acute postoperative pain may be followed by persistent pain in a significant percentage of individuals after common surgical procedures $(5,6)$. This persistent pain may last for more than 3-6 months after surgery (5). Specifically, stump and phantom pain may complicate limb amputations in $5-60 \%$ and $30-80 \%$ of patients respectively, while the incidence of chronic postsurgical pain may range from $50-90 \%$ after breast surgery for cancer (7-9). Chronic pain is also common after thoracotomy (20-70\%), inguinal hernia repair (up to $35 \%$ ), and cholecystectomy (5-50\%) $(5,6)$. Underlying mechanisms may be pertinent to prolonged afferent input of nociceptive signals, originating from surgical trauma (particularly injury affecting nerves) and perioperative inflammatory mechanisms, subsequently leading to alterations mediated by neural plasticity, and eventually central sensiti- 
zation producing chronic pain. Kehlet et al have recognized that iatrogenic neuropathic injury is the most important cause of chronic pain after surgery (5). Furthermore, in the majority of patients, chronic post-surgical pain closely resembles with neuropathic pain (5). These include spontaneous painful sensations within or beyond an operated area (described as paroxysmal lancination, shooting, burning and throbbing pain), hyperalgesia, allodynia, different types of dysesthesia, as well as sensory loss within the area innervated by the damaged nerves.

Risk factors to transition to chronic pain in surgical patients are genetic susceptibility, various psychological and social factors, age and gender, and the intensity of preceding acute postoperative pain. The intensity of acute pain immediately before or after surgery is strongly associated with the incidence and intensity of subsequent chronic post-surgical pain after amputation, after breast surgery, thoracotomy and herniorrhaphy (10). Thus, suppression of this afferent nociceptive traffic by appropriate analgesic strategies, in addition to reducing postoperative pain, may suppress the development of chronic pain after surgery.

The association between intensity of acute postoperative pain and development of chronic pain after surgery implies that inadequate peri- and postoperative analgesia may constitute a significant factor. Thus, in this context, effective pain management should be considered as an essential component of anaesthesia and perioperative medicine. Various surveys have estimated the percentage of patients who experience pain after surgery to range between 30 and $80 \%$, and, of these patients, the majority (more than $80 \%$ ) report the intensity as moderate, severe, or extreme (11).

Traditionally, opioid analgesics have been considered as the mainstay of management of moderate to severe postoperative pain. Advantages of these drugs include their established efficacy, wide availability, experience with their use, and relative ease of administration.
However, side effects such as respiratory depression and hypoxemia, nausea and vomiting, sedation, and delayed recovery of bowel function are limitations of their use. The emerging recognition of opioid-induced hyperalgesia is an additional drawback: it has been shown that repeated administration of opioids intraoperatively induce an acute state of tolerance, hyperalgesia, or both (12-15). The pathophysiology of opioidinduced hyperalgesia is complex, but phenomena of peripheral and central sensitization may be highly pertinent. Mechanisms related to N-Methyl-DAspartate (NMDA) receptor activation and translocation of the protein kinase $\mathrm{C}$ (PKC) in dorsal horn neurons have been implicated in the development of persisting pain, hyperalgesia, and tolerance to opioid analgesia (16-18). Opioid receptor activation results in stimulation of PKC, which phosphorylates several target proteins, including the NMDA receptor, with subsequent downstream activation of a series of cascades that mediate central sensitization and hyperalgesia. PKC stimulation has been also implicated in the process of acute tolerance to opioid analgesia (16-18).

The problems with perioperative opioids have been well recognized $(1,2,4,19,20)$, and these agents today are considered as being very far from ideal analgesics for pain after surgery. It is evident that the traditionally recognized opioidrelated side effects (prolonged drowsiness, sedation, nausea, vomiting and gastrointestinal tract dysfunction) may significantly delay recovery, provide additional sources of postoperative distress and morbidity, and demand additional costs and resources for effective management. In contrast, attempts aiming to improve postoperative analgesia with non-opioid analgesics and techniques, result in opioid sparing effect, reduce side-effects and morbidity, improve patient satisfaction and decrease length of hospitalization or stay in the recovery.

\section{Gabapentin}

Gabapentin (1-(amino-methyl)-cyclohexane acetic acid) is a novel antiepilep- tic agent that has proved to be especially effective at relieving allodynia and hyperalgesia in animal models. Furthermore, it has been shown to be efficacious in numerous small clinical studies and case reports in a wide variety of neuropathic pain syndromes, as well as other types of pain (21). Specifically, gabapentin has been clearly demonstrated to be effective for the treatment of neuropathic pain in diabetic neuropathy $(22,23)$, postherpetic neuralgia (24), trigeminal neuralgia (25), painful neuropathy from HIV infection (26), cancer (27-29), and complex regional pain syndromes $(30,31)$. This supportive evidence, combined with the drug's favourable side-effect profile in various patient groups (including the elderly) and lack of drug interactions, has rendered it an attractive agent for clinical practice. Gabapentin's exact mechanism of action is not quite clear, but most likely involves inhibition of neuronal voltage-gated calcium currents (VGCC) and suppression of excitatory neurotransmitter release.

Gabapentin was originally developed as a gamma-aminobutyric acid (GABA)mimetic compound. The molecular weight of the drug is 171.34, and at physiological $\mathrm{pH}$ it is highly charged, existing as a zwitterion with two pKa values of 3.68 and 10.70 (21).

Although it is stable at room temperature, a small amount of lactam formation occurs in aqueous solutions and this is minimized at a pH of 6.0.

Gabapentin, available only as oral preparations, is absorbed in the small intestine by a combination of diffusion and facilitated transport. Its transport from the gut is facilitated by its binding to a receptor linked to a saturable I-amino acid transport mechanism (32-34). Brain tissue concentrations are $80 \%$ the plasma level. In humans it exists in a highly ionized state at physiological $\mathrm{pH}$ (21). Gabapentin is not metabolized in humans and is eliminated unchanged in the urine. It undergoes first-order kinetic elimination and renal impairment decreases gabapentin elimination in a linear fashion with a good correlation with creatinine clearance. Unlike other anticonvulsant drugs, it does not 
induce or inhibit hepatic microsomal enzymes.

Despite a remarkably successful and safe clinical profile, the drug's exact site or mode of mechanism has not been completely understood (35). In experimental animals gabapentin exerts a potent inhibitory effect in neuropathic pain models of mechanical hyperalgesia and mechanical/thermal allodynia. So far, there is no evidence that gabapentin blocks GABA uptake or metabolism that it binds to GABAA or GABAB receptors, or exerts any GABA-mimetic action $(35,36)$.

Other effects of gabapentin have been described but are not considered to play a significant role with regard to pharmacodynamics. These include small decreases in the release of monoamine neurotransmitters (dopamine, noradrenaline and serotonin) $(37,38)$, and the attenuation of sodium-dependent action potentials (suggesting sodium channel blockade) after prolonged exposure to the drug (39).

Although early studies indicated a central anti-allodynic effect (40), gabapentin has been shown to inhibit ectopic discharge activity from injured peripheral nerves, as well (41). With regards to site of action, Patel et al. demonstrated a presynaptic site of action for gabapentin in the rat spinal cord (42). Field et al. excluded an antihyperalgesic action via opioid receptor binding, after demonstrating that morphine tolerance does not alter the efficacy of gabapentin, and naloxone does not reduce its antihyperalgesic effect (43). Receptor binding studies have also failed to demonstrate a direct binding site for gabapentin at the NMDA receptor (44).

It has also been recognized that the $\alpha_{2} \delta$ subunit of the voltage-gated calcium channels is a binding site for gabapentin and the S-isomer of pregabalin (S-(+)-3-isobutylgaba) (45). Because only gabapentin and the S-isomer of pregabalin produce antihyperalgesic effects, it has been postulated that the antihyperalgesic action for gabapentin is mediated by its binding to this site on the voltage-gated calcium channel (46). The $\alpha_{2} \delta$ subunit regulates the conductance of current flow through the voltage-gated calcium channels (47). Thus, an inhibitory effect of gabapentin on the neuronal calcium channels (especially certain VGCC subtypes, such as $P / Q$ and/or $N$ type) might decrease calcium influx, which might subsequently reduce excitatory amino acid (glutamate) release, leading to decreased postsynaptic excitatory responses (48-51). Otherwise, an enhancement of the calcium influx via VGCC produced by gabapentin, in case of a possible enhancement of VGCC as a result of binding to the $\alpha 2 \delta$ subunit might alternatively reduce the membrane excitability by facilitating $\mathrm{K}+$ efflux via the calciumactivated potassium channels that have been identified on mammalian sensory nociceptive neurons and are altered by nerve injury (52). These speculations may be consistent with the hypothesis that gabapentin modifies voltage-gated calcium channels, in a manner consistent with explaining an antihyperalgesic effect by either mechanism.

Available studies investigating the effects of gabapentin on calcium currents in neuronal cells initially produced controversial results $(44,53,54)$. However, Sarantopoulos et al investigated the effects of gabapentin on the calcium currents in primary afferent neuronal somata, dissociated from rats with experimental nerve injury, sham skin surgery or non-operated, and employing special perforated patch recordings using $\beta$-escin (55), first showed that gabapentin inhibits voltage-gated calcium currents (56), but not ATP-sensitive potassium currents (K ATP) (57). These $K_{\text {ATP }}$ currents may also control excitability and excitatory neurotransmitter release from primary afferent terminals (58-63). Of note is the fact that gabapentin acts as a $\mathrm{K}_{\text {ATP }}$ channel opener in central neurons (5860), wherein inhibits neurotransmitter release via this mechanism, but most likely this is not the case on peripheral nociceptive pathways (57). Nevertheless, the gabapentin effect on VGCC is rapid, concentration-dependent and reversible, and the inhibition is partly voltage dependent (56). Apparently, the antihyperalgesic effect of gabapentin may be explained by the inhibitory action on voltage-gated calcium channels. Inward calcium currents have a well-demonstrated role in mediating several neuronal physiological processes $(64,65)$ including synaptic neurotransmitter release $(66,67)$, and are altered by nociception and neuronal injury $(68,69)$. Additionally, other studies have suggested that gabapentin decreases excitatory neurotransmitter release at presynaptic dorsal horn sites $(42,51)$, a consequence of VGCC inhibition. Inhibition of excitatory neurotransmitter release in the spinal cord may prevent the development of central sensitization and possibly the subsequent establishment of chronic pain.

The pharmacological effects of gabapentin most likely are complex, and have been shown to be mediated at central $(40,70)$, as well as at peripheral sites $(46,56)$. In addition to neuropathic pain, gabapentin has also been shown to suppress pain from inflammatory mechanisms, in a selective and preferential fashion (71). Stanfa et al reported opposing effects of this drug between normal animals, versus animals with painful inflammation: while gabapentin facilitates noxious evoked responses of dorsal horn neurons in the normal animals, in contrast, after inflammation inhibits C-fibres evoked responses and post-discharges, in a fashion indicative of a selective action against inflammatory pain states (71). Kanai et al showed that gabapentin has pro-excitatory effects in normal peripheral sensory neurons, while in injured neurons decreases excitability (72). Sarantopoulos et al showed that gabapentin decreased VGCC in neurons dissociated from rats subjected to experimental surgical nerve injury and sham skin-operated rats, as well as in neurons from non-operated rats. Nevertheless, the gabapentin inhibitory effect in the latter was not as significant as in neurons from rats that had been previously subjected to surgical sciatic nerve injury or sham skin surgery (56). Furthermore, gabapentin suppresses thermal and mechanical hyperalgesia induced in 
a surgical pain model by incision at the rat paw $(73,74)$. Clinically, also, cutaneous secondary hyperalgesia (indicative of central sensitization) induced by heat and capsaicin application in volunteers, can be suppressed or prevented by gabapentin (75).

Because central sensitization may be associated with the development of at least some manifestations of early postoperative pain, as well as with the transition to chronic pain, drugs possessing antihyperalgesic action may suppress both phases of pain.

Considering the antihyperalgesic properties of gabapentin, particularly its capacity to selectively affect nociceptive processes leading to central sensitization, its use in the perioperative setting sounds reasonable.

\section{Gabapentin as postopera- tive analgesic}

The above findings indicate a potential role of gabapentin as a putative "broadspectrum" analgesic $(76,77)$, with a selective antihyperalgesic and antiallodynic action, specifically against pain induced intraoperatively by nerve or tissue injury (77). Gabapentin, may also suppress central sensitization, a major mechanism mediating the transition from acute to chronic pain after surgery, perhaps via an inhibitory effect on VGCC that control presynaptic excitatory neurotransmitter release. Pertinent to the above observation, is the emerging role of gabapentin as a perioperative and postoperative analgesic. The antinociceptive and antihyperalgesic and anti-inflammatory effects of gabapentin in states that emerge after acute nerve injury may have an impact on acute and chronic pain after surgery. Because of the synergism between gabapentin and opioids, the effects of gabapentin on acute postoperative pain and morphine consumption in patients undergoing different types of surgery have been investigated in randomized, controlled double-blind studies. The postoperative analgesic effect has been actually confirmed by systemic reviews that have analyzed series of clinical studies, evaluating gabapentin as a postopera- tive analgesic agent (78). These studies have confirmed that perioperative gabapentin is an effective analgesic and has an opioid sparing effect. The specific effect after different types of surgery is reviewed in the following sections.

\section{Pain after breast surgery}

Two thirds or more of women who undergo breast surgery for cancer will develop chronic pain (7-10,79-81). In addition to physical discomfort, women experiencing chronic pain, after breast surgery for cancer, have poor quality of life, with impaired function and increased psychosocial distress (82-84).

Ongoing, intense acute postoperative pain may be associated with the development of chronic pain after breast surgery. In this context, regarding the efficacy of gabapentin in preventing the development of chronic pain, two pertinent studies by Fassoulaki et al have also documented a preventative effect of perioperative gabapentin after breast surgery for cancer.

First, Fassoulaki et al investigated the analgesic efficacy of mexiletine and gabapentin on acute and chronic pain after breast surgery for cancer in 75 patients (79).

They were randomized to receive, in a double-blind manner, mexiletine 600 mg/d, or gabapentin 1200 mg/d or placebo for 10 days. A significant reduction of postoperative analgesic requirements in patients who received mexiletine or gabapentin were observed.

Mexiletine and gabapentin reduced codeine consumption from the second to tenth day by $50 \%$. Total paracetamol consumption was also reduced during the same time. Pain at rest was reduced by either drug on the third postoperative day, while gabapentin reduced postoperative pain after movement from the second to fifth postoperative day. No side effects, such as dizziness, drowsiness, or ataxia were observed. Three months later, the incidence of burning pain was more frequent in the control group, indicating a preventative effect of perioperative gabapentin on chronic pain as well.
Of note is the finding that in the previous study, gabapentin, although started the day before surgery, decreased pain and produced an analgesic sparing effect only during and after the second postoperative day. Nevertheless, this was not the case in a similar randomized, double-blind, placebo-controlled study by Dirks et al, who administered a single oral dose of gabapentin (1200 mg) or placebo 1 hour before mastectomy (85). Gabapentin produced a opioid-sparing effect (morphine consumption decreased by $50 \%$ ) as well as a significant analgesic effect, evident even at 2 and 4 hours postoperatively.

Pain with movement decreased by $50 \%$ or more, while pain at rest and side effects did not differ.

Fassoulaki et al, also, in a double-blind, randomized controlled study, compared a multimodal analgesic regimen (gabapentin, Eutectic Mixture of Local Anaesthetics -EMLA cream- applied to surgical field, and ropivacaine installation in the brachial plexus area) to placebo (9). Gabapentin was administered at a dose $400 \mathrm{mg}$ orally every 6 hours starting from the day before surgery up to the eighth postoperative day. The group of patients that received gabapentin perioperatively, as part of a multimodal regimen, consumed much less analgesics immediately postoperatively, had less pain at rest on postoperative days 1, 3 and 5, less pain after movement in the PACU and on postoperative days 2,4 and 8, as well as a significantly lower incidence of chronic pain three months after surgery (45\% versus $82 \%$ in the control group). The capacity of gabapentin to prevent chronic pain was attributed to suppression of the ectopic discharge activity from injured peripheral nerves and blockade of the injuryinduced neuronal hyperactivity.

\section{Post-hysterectomy pain}

The effect of gabapentin on postoperative pain and analgesic requirements following abdominal hysterectomy, a common surgical procedure, has been investigated by a series of studies, not necessarily yielding consistent results. Dierking et al, in a randomized, dou- 
ble-blind study investigated the opioid sparing and analgesic effects of gabapentin administered during the first $24 \mathrm{~h}$ after abdominal hysterectomy (86). Gabapentin 1200 mg versus placebo was administered $1 \mathrm{~h}$ before surgery, followed by $600 \mathrm{mg}$ (or placebo) after 8,16 and 24 hours. While pain levels remained the same, gabapentin reduced total postoperative morphine consumption in a fashion dependent on the plasma levels of the drug. No side-effects were detected.

Pain relieving and analgesic-sparing effects have been observed also even after a single preoperative dose of the drug. A randomized, placebo-controlled, double-blind study by Turan et al investigated whether a single dose of 1200 mg gabapentin, administered one hour before surgery, affects pain and tramadol consumption after abdominal hysterectomy (87). Gabapentin decreased both pain scores up to $20 \mathrm{~h}$ after surgery, as well as tramadol consumption at 12, 16, 20, and $24 \mathrm{~h}$, including total consumption compared with placebo group. Sedation scores were similar at all the measured times. There were no differences between groups with regard to sedation and any side effects.

Furthermore, Rorarius et al, also in a double-blind, randomized controlled investigation compared $1200 \mathrm{mg}$ of gabapentin to active placebo (15 mg of oxazepam) administered $2.5 \mathrm{~h}$ prior to induction of anaesthesia to patients undergoing elective vaginal hysterectomy (88). Gabapentin reduced postoperative analgesic consumption by 40\% during the first 20 postoperative hours, pain scores during the first 2 postoperative hours, as well as postoperative nausea and vomiting (because of the decreased postoperative opioid requirements and/or of an anti-emetic effect). Nevertheless, oxazepam was more effective anxiolytic. As was the case in the previous studies, no differences were observed in side effects.

Gilron et al evaluated the effects of gabapentin alone (1800 mg/day), or in combination with rofecoxib (1800/50 $\mathrm{mg}$ /day respectively), or rofecoxib alone (50 mg/day), versus placebo starting 1 hour before abdominal hysterectomy and continuing for 72 hours (89). All treatments decreased pain at rest and movement at 24 hours and morphine consumption at 48 hours, and improved respiratory function measured by peak expiratory flow. Gabapentin was efficacious in reducing pain interference with movement, mood and sleep. Combination with rofecoxib was superior to either single agent for postoperative pain. Thus, combination with other non-opioid analgesics may confer significant benefits such as opioid sparing, reduced interference with movement, mood and sleep and accelerated pulmonary recovery.

Turan et al found similar results, with gabapentin $1200 \mathrm{mg} / \mathrm{d}$ alone, in combination with $50 \mathrm{mg} / \mathrm{d}$ rofecoxib and rofecoxib alone, versus placebo, administered before and for 2 hours after abdominal hysterectomy (90). All three treatments decreased pain scores and produced an opioid sparing effect versus control, which led to a faster recovery of bowel function. Seventy-two hours postoperatively, patients who had received combination treatment reported the highest satisfaction rate. Both these studies indicate a significant potential of the gabapentin as part of multimodal analgesia schemes facilitating recovery after lower abdominal surgical procedures.

These results are not reproducible by all studies. Fassoulaki et al investigated the effects of gabapentin 400 mg 6 hourly or placebo, administered from 18 hours preoperatively and continued for 5 postoperative days, on acute as well as on chronic postoperative pain one month after abdominal hysterectomy as well (91). Gabapentin had no effect on the acute postoperative pain and on postoperative analgesic requirements. Nevertheless, chronic pain in the surgical area one month after surgery was decreased from $81 \%$ in the control group to $36 \%$ in the gabapentin group. The intensity of pain at that time was also decreased. The same investigators evaluated the combination of gabapentin 400 mg 6 hourly for 7 days with continuous wound irrigation with $0.75 \%$ ropivacaine for 30 hours, versus placebo (92). In combination with local aesthetic, gabapentin did produce an early analgesic effects as well, evident in a significant opioid sparing effect starting immediately after surgery and continuing for up to the $7^{\text {th }}$ postoperative day. In addition, one month postoperatively fewer patients in the treatment group experienced chronic pain than in the control group.

\section{Pain after spinal surgery}

The potential analgesic and opioidsparing effect of gabapentin was evaluated also after spinal surgery, but different studies yield controversial results. In a relevant randomized, placebo-controlled, double-blind study, Turan et al investigated $1200 \mathrm{mg}$ of gabapentin, administered $1 \mathrm{~h}$ before spinal surgery (elective lumbar discectomy or spinal fusion), versus placebo. Gabapentin resulted in a significant analgesic effect at 1, 2 and 4 hours after surgery, a morphine-sparing effect, as well as reduction in the incidence of vomiting and urinary retention (93).

Pandey et al, similarly, reported that gabapentin (300 mg) administered prior to single-level lumbar discoidectomy significantly decreased both the severity of postoperative pain at all time intervals up to 24 hours, as well as postoperative opioid requirements during the same time interval (94).

However, in another randomized-controlled, double-blind study gabapentin $800 \mathrm{mg}$ administered preoperatively before elective lumbar laminectomy or discectomy failed to decrease pain or morphine requirements in the immediate postoperative period after lumbar laminectomy and discectomy (95).

It is unlikely that this discrepancy may be explained by the a dose-response effect, as in the study by Pandey et al, a much lower dose of $300 \mathrm{mg}$ resulted in a positive effect. Furthermore, in a dose-response study, gabapentin, up to $600 \mathrm{mg}, 2$ hours before surgery produced an analgesic and opioid sparing effect versus placebo in a dosedependent manner (96). Increasing the dose of gabapentin from 600 to 1200 mg did not decrease pain, or opioid 
requirements any further. So, based on these results, gabapentin $600 \mathrm{mg}$ is the optimal dose for postoperative analgesia after lumbar discectomy.

\section{Post-amputation pain}

Pain in the stump of the residual limb (stump pain), or referred to the missing limb (phantom pain) frequently follows amputation, affecting a high percentage (60\%-80\%) of amputees (97-100). Although the prevalence of both of these painful syndromes subsides over time, some patients continue suffering from pain, of intensity severe enough to affect their quality of life. Post-amputation pain syndromes are usually difficult to treat. Tricyclic antidepressants have shown equivocal efficacy and their use may be limited by side effects, but monotherapy with gabapentin up to $2400 \mathrm{mg}$ daily was better than placebo in relieving phantom pain at 6 weeks' treatment (101). Thus, Nikolajsen et al investigated whether postoperative treatment with gabapentin could reduce postamputation stump and phantom pain (102). Patients received placebo, or gabapentin started on the first postoperative day after amputation, gradually increased up to $2400 \mathrm{mg} /$ day, and continued for 30 days. However, gabapentin failed to reduce the incidence or intensity of post-amputation pain, at short term (30 days) or long term (up to 6 months).

\section{Pain after orthopedic surgery}

Gabapentin in most previous studies decreased postoperative pain (including pain with movement) and/or postoperative opioid consumption, but these studies did not include any patients requiring mobilization after joint surgery. To investigate the gabapentin effect in the latter patient population, Menigaux et al administered $1200 \mathrm{mg}$ oral gabapentin or placebo 1-2 $\mathrm{h}$ before anterior cruciate ligament repair under general anaesthesia (103). Gabapentin decreased preoperative anxiety scores; postoperative pain scores (both at rest and after mobilization and physiotherapy) at days 1 and 2, and was associated with more extensive range of motion and less morphine consumption within the same time interval. In addition, the same group of authors, administered oral gabapentin 800 mg versus placebo, 2 hours before arthroscopic shoulder surgery, but in this case the drug did not augment postoperative analgesia provided by interscalene brachial plexus (104).

Pain after Ear, nose and throat (ENT) surgery In a randomized, double-blind, placebo-controlled study, Mikkelsen et al investigated the effect of gabapentin 1200 mg before tonsillectomy in adults, followed by gabapentin 1200 $\mathrm{mg}$ on the day of operation and 1800 $\mathrm{mg}$ for the next 5 days, versus placebo, in combination with rofecoxib $50 \mathrm{mg}$ daily (105). Gabapentin reduced rescue opioid analgesic requirements the first 24 hours, but at the cost of more side effects such as dizziness, gait disturbance and vomiting.

Turan et al reported that gabapentin (1200 mg $1 \mathrm{~h}$ before rhinoplasty or endoscopic sinus surgery under monitored anaesthesia care) conferred significant intraoperative and postoperative analgesia and reduced opioid and non-opioid analgesic requirements, but at cost of higher incidence side-effects (106).

\section{Pain after other surgical procedures}

Pain after laparoscopic cholecystectomy Gabapentin administered preoperatively significantly decreases postoperative pain and analgesic requirements following laparoscopic cholecystectomy. Pandey et al administered 300 mg gabapentin, 100 mg tramadol or placebo in a double-blind manner two hours before laparoscopic cholecystectomy under general anaesthesia. Gabapentin decreased pain and opioid requirements at all time intervals compared to tramadol and placebo, but more sedation, nausea and vomiting were a drawback (107).

\section{Post-thoracotomy pain}

Pain with neuropathic characteristics, commonly ensues after thoracic surgery and trauma, and it may be refractory to conventional analgesic strategies.
Sihoe et al. tried gabapentin on 60 consecutive patients with refractory pain persisting at four weeks or more after thoracic surgery or trauma. Gabapentin may relieve refractory thoracic pain and paresthesiae in approximately $75 \%$ of patients (108). The incidence of minor side effects (somnolence and dizziness) was $40 \%$, while overall satisfaction rates were $90 \%$.

\section{Enhancement of epidural analgesia}

Turan et al investigated gabapentin as an adjunct for postoperative analgesia using patient-controlled epidural analgesia (PCEA) (109). In patients who received $P C E A$ after lower extremity surgery procedures, gabapentin (1200 mg daily before and for 2 days after surgery) decreased pain scores at 1, 4, 8, 12 , and $16 \mathrm{~h}$, PCEA bolus requirements at 24, 48 and 72 hours and paracetamol consumption, versus placebo.

However, time to return of bowel function, duration of hospitalization, and resumption of oral diet did not differ, while the incidence of dizziness was higher in the gabapentin group. Nevertheless, despite more dizziness, patient satisfaction was higher amongst patients who received gabapentin.

\section{Conclusion}

Most of these studies have shown that either single preoperative or repeated doses of gabapentin, continued for up to a few days after surgery, decrease acute postoperative pain and/or need for postoperative opioids. This has been shown for procedures such as abdominal and vaginal hysterectomy, breast surgery for cancer, lumbar discectomy and spinal fusion, laparoscopic cholecystectomy, orthopedic surgery and ENT surgery. Reduced opioid consumption may translate into fewer opioid related unwanted effects with an impact on postoperative recovery, but this is not quite clear yet. In a few studies, gabapentin resulted in side effects such as dizziness and drowsiness. More studies are needed to determine the optimal dose and duration of administration for different types of surgery, especially considering the 
capacity of prolonged administration of gabapentin postoperatively, to prevent the development of chronic pain. Development of central sensitization, as a result of afferent nociceptive input and neuronal hyperexcitability may underlie the pathogenesis of chronic pain. Gabapentin, by reducing the noxious stimuli-induced excitatory neurotransmitter release may prevent central sensitization and subsequent generation of chronic pain after surgery.

\section{REFERENCES}

1. Chung F, Ritchie E, Su J. Postoperative pain in ambulatory surgery. Anesth Analg 1997;85:808-16.

2. Chung F, Un V, Su J. Postoperative symptoms 24 hours after ambulatory anaesthesia. Can J Anaesth 1996;43:1121-27.

3. Gold BS, Kitz DS, Lecky JH, Neuhaus JM. Unanticipated admission to the hospital following ambulatory surgery. JAMA 1989;262:3008-10.

4. Pavlin DJ, Rapp SE, Polissar NL, Malmgren JA, Koerschgen M, Keyes H. Factors affecting discharge time in adult outpatients. Anesth Analg 1998;87:816-26.

5. Kehlet H, Jensen TS, Woolf CJ. Persistent postsurgical pain: risk factors and prevention. Lancet 2006;367:1618-25.

6. Perkins FM, Kehlet H. Chronic pain as an outcome of surgery. A review of predictive factors. Anesthesiology 2000;93:1123-33.

7. Fassoulaki A, Sarantopoulos C, Melemeni A, Hogan Q. EMLA reduces acute and chronic pain after breast surgery for cancer. Reg Anesth Pain Med 2000;25:350-55.

8. Fassoulaki A, Sarantopoulos C, Melemeni A, Hogan Q. Regional block and mexiletine: the effect on pain after cancer breast surgery. Reg Anesth Pain Med 2001;26:223-28.

9. Fassoulaki A, Triga A, Melemeni A, Sarantopoulos C. Multimodal analgesia with gabapentin and local anesthetics prevents acute and chronic pain after breast surgery for cancer. Anesth Analg 2005;101:1427-32.

10. Poleshuck EL, Katz J, Andrus CH, Hogan LA, Jung BF, Kulick DI, Dworkin RH. Risk factors for chronic pain following breast cancer surgery: a prospective study. J Pain 2006;7:626-34.

11. Apfelbaum JL, Chen C, Mehta SS, Gan TJ. Postoperative pain experience: results from a national survey suggest postoperative pain continues to be undermanaged. Anesth Analg 2003;97:534-40.

12. Chia YY, Liu K, Wang JJ, Kuo MC, Ho ST. Intraoperative high dose fentanyl induces postoperative fentanyl tolerance. Can J Anaesth 1999;46:872-77.

13. Guignard B, Bossard AE, Coste C, Sessler DI, Lebrault C, Alfonsi P, Fletcher D, Chauvin M. Acute opioid tolerance: intraoperative remifentanil increases postoperative pain and morphine requirement. Anesthesiology 2000;93:409-17.

14. Li X, Angst MS, Clark JD. Opioid-induced hyperalgesia and incisional pain. Anesth Analg 2001;93:204-09.

15. Vinik HR, Kissin I. Rapid development of tolerance to analgesia during remifentanil infusion in humans. Anesth Analg 1998;86:1307-11.

16. Law PY, Wong YH, Loh HH. Molecular mechanisms and regulation of opioid receptor signalling. Annu Rev Pharmacol Toxicol 2000;40:389-430.

17. Ueda H, Inoue M, Matsumoto T. Protein kinase C-mediated inhibition of mu-opioid receptor internalization and its involvement in the development of acute tolerance to peripheral mu-agonist analgesia. J Neurosci 2001;21:2967-73.

18. Ueda H, Inoue M, Mizuno K. New approaches to study the development of morphine tolerance and dependence. Life Sci 2003;74:313-20.

19. Chung F, Mezei G. Factors contributing to a prolonged stay after ambulatory surgery. Anesth Analg 1999;89:1352-59.

20. White PF. The role of non-opioid analgesic techniques in the management of pain after ambulatory surgery. Anesth Analg 2002;94:577-85.

21. Rose MA, Kam PC. Gabapentin: pharmacology and its use in pain management. Anaesthesia 2002;57:451-62.

22. Backonja M, Beydoun A, Edwards KR, Schwartz SL, Fonseca V, Hes M, LaMoreaux L, Garofalo E. Gabapentin for the symptomatic treatment of painful neuropathy in patients with diabetes mellitus: a randomized controlled trial. JAMA 1998;280:1831-36.

23. Backonja MM. Gabapentin monotherapy for the symptomatic treatment of painful neuropathy: a multicenter, double-blind, placebocontrolled trial in patients with diabetes mellitus. Epilepsia 1999;40 Suppl 6:S57-59.

24. Rowbotham M, Harden N, Stacey B, Bernstein P, Magnus-Miller L. Gabapentin for the treatment of postherpetic neuralgia: a randomized controlled trial. JAMA 1998; 280:1837-42.

25. Khan OA. Gabapentin relieves trigeminal neuralgia in multiple sclerosis patients. Neurology 1998;51:611-14.

26. Newshan G. HIV neuropathy treated with gabapentin. AIDS 1998;12:219-21.

27. Caraceni A, Zecca E, Bonezzi C, Arcuri E, Yaya Tur R, Maltoni M, et al. Gabapentin for neuropathic cancer pain: a randomized controlled trial from the Gabapentin Cancer Pain Study Group. J Clin Oncol 2004;22:2909-17.

28. Caraceni A, Zecca E, Martini C, De Conno F. Gabapentin as an adjuvant to opioid analgesia for neuropathic cancer pain. J Pain Symptom Manage 1999;17:441-45.

29. Caraceni A, Zecca E, Martini C, De Conno F. Differences in gabapentin efficacy for cancer pain more apparent than real? J Pain Symptom Manage 2001;21:93-94.

30. Mellick GA, Mellick LB. Reflex sympathetic dystrophy treated with gabapentin. Arch Phys Med Rehabil 1997;78:98-105. 
31. Mellick GA, Mellicy LB, Mellick LB. Gabapentin in the management of reflex sympathetic dystrophy. J Pain Symptom Manage 1995;10:26566.

32. Thurlow RJ, Brown JP, Gee NS, Hill DR, Woodruff GN. Š3HĆ gabapentin may label a system-L-like neutral amino acid carrier in brain. Eur J Pharmacol 1993;247:341-45.

33. Thurlow RJ, Hill DR, Woodruff GN. Comparison of the autoradiographic binding distribution of (3H)-gabapentin with excitatory amino acid receptor and amino acid uptake site distributions in rat brain. Br J Pharmacol 1996;118: 457-65.

34. Thurlow RJ, Hill DR, Woodruff GN. Comparison of the uptake of Š3HĆ-gabapentin with the uptake of L-Š3HĆ-leucine into rat brain synaptosomes. Br J Pharmacol 1996;118:449-56.

35. Taylor CP, Gee NS, Su TZ, Kocsis JD, Welty DF, Brown JP, Dooley DJ, Boden P, Singh L. A summary of mechanistic hypotheses of gabapentin pharmacology. Epilepsy Res 1998;29:233-49

36. Taylor CP, Vartanian MG, Yuen PW, Bigge C, Suman-Chauhan N, Hill DR. Potent and stereospecific anticonvulsant activity of 3-isobutyl GABA relates to in vitro binding at a novel site labeled by tritiated gabapentin. Epilepsy Res 1993;14:11-15.

37. Reimann W. Inhibition by GABA, baclofen and gabapentin of dopamine release from rabbit caudate nucleus: are there common or different sites of action? Eur J Pharmacol 1983;94: 341-44.

38. Schlicker E, Reimann W, Gothert M. Gabapentin decreases monoamine release without affecting acetylcholine release in the brain. Arzneimittelforschung 1985;35:1347-49

39. Wamil AW, McLean MJ. Limitation by gabapentin of high frequency action potential firing by mouse central neurons in cell culture. Epilepsy Res 1994;17:1-11

40. Abdi S, Lee DH, Chung JM. The anti-allodynic effects of amitriptyline, gabapentin, and lidocaine in a rat model of neuropathic pain. Anesth Analg 1998;87:1360-66.

41. Pan HL, Eisenach JC, Chen SR. Gabapentin suppresses ectopic nerve discharges and reverses allodynia in neuropathic rats. J Pharmacol Exp Ther 1999;288:1026-30.

42. Patel MK, Gonzalez MI, Bramwell S, Pinnock RD, Lee K. Gabapentin inhibits excitatory synaptic transmission in the hyperalgesic spinal cord. Br J Pharmacol 2000;130:1731-34.

43. Field MJ, Oles RJ, Lewis AS, McCleary S, Hughes J, Singh L. Gabapentin (neurontin) and S-(+)-3-isobutylgaba represent a novel class of selective antihyperalgesic agents. Br J Pharmacol 1997;121:1513-22.

44. Rock DM, Kelly KM, Macdonald RL. Gabapentin actions on ligand- and voltage-gated responses in cultured rodent neurons. Epilepsy Res 1993;16:89-98.

45. Gee NS, Brown JP, Dissanayake VU, Offord J, Thurlow R, Woodruff GN. The novel anticonvulsant drug, gabapentin (Neurontin), binds to the alpha2delta subunit of a calcium channel. J Biol Chem 1996;271:5768-76.

46. Carlton SM, Zhou S. Attenuation of formalin-induced nociceptive behaviors following local peripheral injection of gabapentin. Pain 1998;76:201-07.

47. Shistik E, Ivanina T, Puri T, Hosey M, Dascal N. Ca2+ current enhancement by alpha 2/delta and beta subunits in Xenopus oocytes: contribution of changes in channel gating and alpha 1 protein level. J Physiol 1995;489( Pt 1):55-62.

48. Dooley DJ, Donovan CM, Meder WP, Whetzel SZ. Preferential action of gabapentin and pregabalin at P/Q-type voltage-sensitive calcium channels: inhibition of $\mathrm{K}+$-evoked (3H)-norepinephrine release from rat neocortical slices. Synapse 2002;45:171-90.

49. Dooley DJ, Mieske CA, Borosky SA. Inhibition of $\mathrm{K}(+)$-evoked glutamate release from rat neocortical and hippocampal slices by gabapentin. Neurosci Lett 2000;280:107-10.

50. Fink K, Meder W, Dooley DJ, Gothert M. Inhibition of neuronal Ca(2+) influx by gabapentin and subsequent reduction of neurotransmitter release from rat neocortical slices. Br J Pharmacol 2000;130:900-06.

51. Shimoyama M, Shimoyama N, Hori Y. Gabapentin affects glutamatergic excitatory neurotransmission in the rat dorsal horn. Pain 2000;85:405-14

52. Sarantopoulos CD, McCallum JB, Rigaud M, Fuchs A, Kwok WM, Hogan QH. Opposing effects of spinal nerve ligation on calciumactivated potassium currents in axotomized and adjacent mammalian primary afferent neurons. Brain Res 2006 (In Press) Available from URL: http://dx.doi.org/10.1016/j.brainres.2006.11.055

53. Stefani A, Spadoni F, Bernardi G. Gabapentin inhibits calcium currents in isolated rat brain neurons. Neuropharmacology 1998;37:83-91.

54. Stefani A, Spadoni F, Giacomini P, Lavaroni F, Bernardi G. The effects of gabapentin on different ligand- and voltage-gated currents in isolated cortical neurons. Epilepsy Res 2001;43:239-48

55. Sarantopoulos C, McCallum JB, Kwok WM, Hogan Q. Beta-escin diminishes voltage-gated calcium current rundown in perforated patchclamp recordings from rat primary afferent neurons. J Neurosci Methods 2004;139:61-68.

56. Sarantopoulos C, McCallum B, Kwok WM, Hogan Q. Gabapentin decreases membrane calcium currents in injured as well as in control mammalian primary afferent neurons. Reg Anesth Pain Med 2002;27:47-57.

57. Sarantopoulos C, McCallum B, Sapunar D, Kwok WM, Hogan Q. ATP-sensitive potassium channels in rat primary afferent neurons: the effect of neuropathic injury and gabapentin. Neurosci Lett 2003;343:185-89.

58. Freiman TM, Kukolja J, Heinemeyer J, Eckhardt K, Aranda H, Rominger A. Modulation of K+-evoked (3H)-noradrenalin release from rat 
and human brain slices by gabapentin: involvement of KATP channels. Naunyn Schmiedebergs Arch Pharmacol 2001;363:537-42.

59. Freiman TM, Surges R, Kukolja J, Heinemeyer J, Klar M, van Velthoven V, Zentner J. K(+)-evoked ((3)H)-norepinephrine release in human brain slices from epileptic and non-epileptic patients is differentially modulated by gabapentin and pinacidil.

Neurosci Res 2006;55:204-10.

60. Jehle T, Lagreze WA, Blauth E, Knorle R, Schnierle P, Lucking CH. Gabapentin-lactam (8-aza-spiro Š5,4Ć decan-9-on; GBP-L) inhibits oxygen glucose deprivation-induced $(3 \mathrm{H})$-glutamate release and is a neuroprotective agent in a model of acute retinal ischemia. Naunyn Schmiedebergs Arch Pharmacol 2000;362:74-81.

61. Jiang C, Haddad GG. Modulation of K+ channels by intracellular ATP in human neocortical neurons. J Neurophysiol 1997;77:93-102.

62. Politi DM, Rogawski MA. Glyburide-sensitive K+ channels in cultured rat hippocampal neurons: activation by cromakalim and energydepleting conditions. Mol Pharmacol 1991;40:308-15.

63. Stefani MR, Nicholson GM, Gold PE. ATP-sensitive potassium channel blockade enhances spontaneous alternation performance in the rat: a potential mechanism for glucose-mediated memory enhancement. Neuroscience 1999;93:557-63.

64. Ghosh A, Ginty DD, Bading H, Greenberg ME. Calcium regulation of gene expression in neuronal cells. J Neurobiol 1994;25:294-303.

65. Ghosh A, Greenberg ME. Calcium signaling in neurons: molecular mechanisms and cellular consequences. Science 1995;268:239-47.

66. Meir A, Ginsburg S, Butkevich A, Kachalsky SG, Kaiserman I, Ahdut R, et al. Ion channels in presynaptic nerve terminals and control of transmitter release. Physiol Rev 1999;79:1019-88.

67. Takahashi T, Momiyama A. Different types of calcium channels mediate central synaptic transmission. Nature 1993;366:156-58.

68. Chaplan SR, Pogrel JW, Yaksh TL. Role of voltage-dependent calcium channel subtypes in experimental tactile allodynia. J Pharmacol Exp Ther 1994;269:1117-23.

69. Hogan QH, McCallum JB, Sarantopoulos C, Aason M, Mynlieff M, Kwok WM, Bosnjak ZJ. Painful neuropathy decreases membrane calcium current in mammalian primary afferent neurons. Pain 2000;86:43-53.

70. Attal N, Brasseur L, Parker F, Chauvin M, Bouhassira D. Effects of gabapentin on the different components of peripheral and central neuropathic pain syndromes: a pilot study. Eur Neurol 1998;40:191-200.

71. Stanfa LC, Singh L, Williams RG, Dickenson AH. Gabapentin, ineffective in normal rats, markedly reduces C-fibre evoked responses after inflammation. Neuroreport 1997:8:587-90.

72. Kanai A, Sarantopoulos C, McCallum JB, Hogan Q. Painful neuropathy alters the effect of gabapentin on sensory neuron excitability in rats. Acta Anaesthesiol Scand 2004;48:507-12.

73. Field MJ, Holloman EF, McCleary S, Hughes J, Singh L. Evaluation of gabapentin and S-(+)-3-isobutylgaba in a rat model of postoperative pain. J Pharmacol Exp Ther 1997;282:1242-46.

74. Whiteside GT, Harrison J, Boulet J, Mark L, Pearson M, Gottshall S, Walker K. Pharmacological characterisation of a rat model of incisional pain. Br J Pharmacol 2004;141:85-91.

75. Dirks J, Petersen KL, Rowbotham MC, Dahl JB. Gabapentin suppresses cutaneous hyperalgesia following heat-capsaicin sensitization. Anesthesiology 2002; 97:102-07.

76. Gilron I. Is gabapentin a „Broad-spectrum" analgesic? Anesthesiology 2002;97:537- 39.

77. Rowbotham DJ. Gabapentin: a new drug for postoperative pain? Br J Anaesth 2006;96:152-55.

78. Ho KY, Gan TJ, Habib AS. Gabapentin and postoperative pain-a systematic review of randomized controlled trials. Pain 2006;126:91-101.

79. Fassoulaki A, Patris K, Sarantopoulos C, Hogan Q. The analgesic effect of gabapentin and mexiletine after breast surgery for cancer. Anesth Analg 2002;95:985-91.

80. Macdonald L, Bruce J, Scott NW, Smith WC, Chambers WA. Long-term follow-up of breast cancer survivors with post-mastectomy pain syndrome. Br J Cancer 2005;92: 225-30.

81. Tasmuth T, von Smitten K, Hietanen P, Kataja M, Kalso E. Pain and other symptoms after different treatment modalities of breast cancer. Ann Oncol 1995;6:453-59.

82. Akechi T, Okuyama T, Imoto S, Yamawaki S, Uchitomi Y. Biomedical and psychosocial determinants of psychiatric morbidity among postoperative ambulatory breast cancer patients. Breast Cancer Res Treat 2001;65:195-202.

83. Miaskowski C, Dibble SL. The problem of pain in outpatients with breast cancer. Oncol Nurs Forum 1995;22:791-97.

84. Stevens PE, Dibble SL, Miaskowski C. Prevalence, characteristics, and impact of postmastectomy pain syndrome: an investigation of womenžs experiences. Pain 1995;61:61-68.

85. Dirks J, Fredensborg BB, Christensen D, Fomsgaard JS, Flyger H, Dahl JB. A randomized study of the effects of single-dose gabapentin versus placebo on postoperative pain and morphine consumption after mastectomy. Anesthesiology 2002;97:560-64.

86. Dierking G, Duedahl TH, Rasmussen ML, Fomsgaard JS, Moiniche S, Romsing J. Effects of gabapentin on postoperative morphine consumption and pain after abdominal hysterectomy: a randomized, double-blind trial. Acta Anaesthesiol Scand 2004;48:322-27.

87. Turan A, Karamanlioglu B, Memis D, Usar P, Pamukcu Z, Ture M. The analgesic effects of gabapentin after total abdominal hysterectomy. Anesth Analg 2004;98:1370-73.

88. Rorarius MG, Mennander S, Suominen P, Rintala S, Puura A, Pirhonen R, Salmelin R, Haanpaa M, Kujansuu E, Yli-Hankala A. Gabapentin for the prevention of postoperative pain after vaginal hysterectomy. Pain 2004;110:175-81. 
89. Gilron I, Orr E, Tu D, O'Neill JP, Zamora JE, Bell AC. A placebo-controlled randomized clinical trial of perioperative administration of gabapentin, rofecoxib and their combination for spontaneous and movement-evoked pain after abdominal hysterectomy. Pain 2005;113:191-200.

90. Turan A, White PF, Karamanlioglu B, Memis D, Tasdogan M, Pamukcu Z, Yavuz E. Gabapentin: an alternative to the cyclooxygenase-2 inhibitors for perioperative pain management. Anesth Analg 2006;102:175-81.

91. Fassoulaki A, Stamatakis E, Petropoulos G, Siafaka I, Hassiakos D, Sarantopoulos C. Gabapentin attenuates late but not acute pain after abdominal hysterectomy. Eur J Anaesthesiol 2006;23:136-41.

92. Fassoulaki A., Melemeni A., Stamatakis E., Petropoulos G., Sarantopoulos C. A combination of gabapentil and local anaesthetics attenuates acute and late pain after abdominal hysterectomy. Eur J Anaesthesiol 2007 (In press).

93. Turan A, Karamanlioglu B, Memis D, Hamamcioglu MK, Tukenmez B, Pamukcu Z. Analgesic effects of gabapentin after spinal surgery. Anesthesiology 2004;100:935-38.

94. Pandey CK, Sahay S, Gupta D, Ambesh SP, Singh RB, Raza M, Singh U, Singh PK. Preemptive gabapentin decreases postoperative pain after lumbar discoidectomy. Can J Anaesth 2004;51:986-89.

95. Radhakrishnan M, Bithal PK, Chaturvedi A. Effect of preemptive gabapentin on postoperative pain relief and morphine consumption following lumbar laminectomy and discectomy: a randomized, double-blinded, placebo-controlled study. J Neurosurg Anesthesiol 2005; 17:125-28.

96. Pandey CK, Navkar DV, Giri PJ, Raza M, Behari S, Singh RB, Singh U, Singh PK. Evaluation of the optimal preemptive dose of gabapentin for postoperative pain relief after lumbar diskectomy: a randomized, double-blind, placebo-controlled study. J Neurosurg Anesthesiol 2005; 17: 65-68.

97. Jensen TS, Krebs B, Nielsen J, Rasmussen P. Phantom limb, phantom pain and stump pain in amputees during the first 6 months following limb amputation. Pain 1983;17:243-56.

98. Jensen TS, Krebs B, Nielsen J, Rasmussen P. Non-painful phantom limb phenomena in amputees: incidence, clinical characteristics and temporal course. Acta Neurol Scand 1984;70:407-14.

99. Jensen TS, Krebs B, Nielsen J, Rasmussen P. Immediate and long-term phantom limb pain in amputees: incidence, clinical characteristics and relationship to preamputation limb pain. Pain 1985;21:267-78.

100. Nikolajsen L, Illkjaer S, Kroner K, Christensen JH, Jensen TS. The influence of preamputation pain on postamputation stump and phantom pain. Pain 1997;72:393- 405.

101. Bone M, Critchley P, Buggy DJ. Gabapentin in postamputation phantom limb pain: a randomized, double-blind, placebo-controlled, cross-over study. Reg Anesth Pain Med 2002;27:481-86.

102. Nikolajsen L, Finnerup NB, Kramp S, Vimtrup AS, Keller J, Jensen TS. A randomized study of the effects of gabapentin on postamputation pain. Anesthesiology 2006;105:1008-15.

103. Menigaux C, Adam F, Guignard B, Sessler DI, Chauvin M. Preoperative gabapentin decreases anxiety and improves early functional recovery from knee surgery. Anesth Analg 2005;100:1394-99.

104. Adam F, Menigaux C, Sessler DI, Chauvin M. A single preoperative dose of gabapentin (800 milligrams) does not augment postoperative analgesia in patients given interscalene brachial plexus blocks for arthroscopic shoulder surgery. Anesth Analg 2006;103:1278-82.

105. Mikkelsen S, Hilsted KL, Andersen PJ, Hjortso NC, Enggaard TP, Jorgensen DG, Hansen M, Henriksen J, Dahl JB. The effect of gabapentin on post-operative pain following tonsillectomy in adults.Acta Anaesthesiol Scand 2006;50:809-15.

106. Turan A, Memis D, Karamanlioglu B, Yagiz R, Pamukcu Z, Yavuz E. The analgesic effects of gabapentin in monitored anesthesia care for ear-nose-throat surgery. Anesth Analg 2004;99:375-78.

107. Pandey CK, Priye S, Singh S, Singh U, Singh RB, Singh PK. Preemptive use of gabapentin significantly decreases postoperative pain and 